ARTIG0

Recebido em: 27/09/2017

Aceito em: $15 / 03 / 2018$

\title{
Aplicação do modelo Servqual na bienal do livro da Zona da Mata: o olhar dos interagentes abrindo novas páginas para melhoria da qualidade
}

\author{
Application of the Servqual model in the biennial of the Zona da \\ Mata book: the view of the interactant opening new pages for \\ quality improvement
}

\author{
Ana Claudia Borges CAMPOS (anaborges32@hotmail.com)* \\ Marcelo Calderari MIGUEL (marcelocalderari@yahoo.com.br)** \\ Sandra Maria Souza de CARVALHO (sandramaria.carvalho@edu.vilavelha.es.gov.br)*** \\ * Professora Drª da Universidade do Federal do Espírito Santo, Departamento de Biblioteconomia, \\ Campus de Goiabeiras/Vitória - ES. \\ ** Especialista em Educação Científica pela Universidade Federal de Minas Gerais, Bacharel em \\ Biblioteconomia pela Universidade do Federal do Espírito Santo - UFES. \\ *** Bacharela em Biblioteconomia pela Universidade do Federal do Espírito Santo - UFES, \\ Bibliotecária escolar na rede municipal de educação de Vila Velha - ES.
}

\section{Resumo}

Esta pesquisa trata das percepções e expectativas dos visitantes sobre os serviços ofertados na Bienal do Livro da Zona Da Mata, em Juiz de Fora - Minas Gerais (Brasil). Apresenta um estudo exploratório, descritivo, de abordagem quantitativa, visando diagnosticar as dimensões da qualidade: Confiabilidade, Empatia, Garantia, Receptividade e Tangibilidade. Por meio de um questionário Likert foram coletados, de forma não probabilística, dados entre os dias 14 a 19 de junho de 2016. Os resultados indicam a validade e consistência da abordagem, evidência que a maior lacuna abrange os itens tangíveis. Conclui-se que a métrica Servqual é adequada para empoderar os interagentes e pautar possíveis melhorias no processo de desenvolvimento de serviços.

Palavras-chave: Estudo de Usuários. Qualidade. Satisfação. Serviços. Servqual.

\begin{abstract}
This paper deals with visitors' perceptions and expectations about the services offered at the Zona da Mata Book Biennial, in Juiz de Fora city - Minas Gerais State (Brazil). It presents an exploratory, descriptive, quantitative approach, aiming to diagnose the dimensions of quality: Reliability, Empathy, Assurance, Responsiveness and Tangibility. Using a Likert questionnaire, non-probabilistic data were collected between June 14 and 19, 2016. The results indicate the validity and consistency of the approach, evidencing that the largest gap covers tangible items. It is concluded that the Servqual metric is adequate to empower the interactant and to guide possible improvements in the service development process.

Keywords: Study of Users. Quality. Satisfaction. Services. Servqual.
\end{abstract}

v. 23, n. 52,2018

$$
\text { p. } 84-94
$$

ISSN 1518-2924

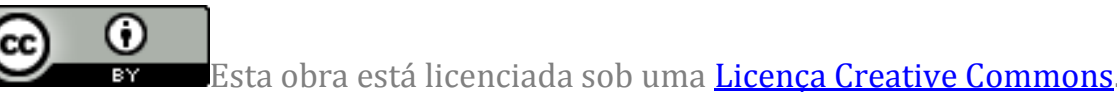




\section{INTRODUÇÃO}

O presente artigo aborda o seguinte problema: quais 'percepções e expectativas' têm a clientela da $1^{\text {a }}$ Bienal do Livro de Juiz de Fora sobre os serviços ofertados? Essa investigação tem por objetivo averiguar a qualidade dos serviços prestados na $1^{\text {a }}$ Bienal tendo como foco os múltiplos olhares dos visitantes diante o processo de desenvolvimento dos serviços. A metodologia utiliza uma releitura da abordagem teórico-metodológica Servqual de Parasuraman, Zeithaml e Berry (1985) e, questionários são usados a fim de diagnosticar o serviço ofertado na bienal e captar desejos e necessidades do público da feira. Esse estudo apresenta uma tendência em espaços não formais de educação mostrando que é importante avaliar e aprimorar visando a clientela.

Miguel e Freire (2016) alertam para crescente utilização da metodologia Servqual em espaço não formal de educação, enquanto modus operandi, demonstra sinalizar uma tendência pela qualidade - a qual infiltra-se paulatinamente como instrumento avaliativo em serviços de museus, jardins botânicos e bibliotecas, porém não se tem notícia de sua aplicação em feiras literárias. Portanto, é uma oportunidade poder discutir a avaliação da qualidade em ambientes não formais de ensino, principalmente na criação da 1aㅡ Bienal do Livro (evento literário em uma cidade do interior) em tempo que os cortes financeiros que tem subjugado a educação a um modelo de gestão indubitavelmente precarizada em termos de produtos e serviços. E o livro enquanto produto é à primeira mercadoria industrial produzida em massa no sentido moderno (BURKE, 2012).

Para Assumção (2000), eventos como a feira do livro servem para mostrar que a leitura ainda tem espaço em meio ao crescente uso da tecnologia e, somente quem lê compreende melhor o que está à sua volta, potencializa a vida e transforma a realidade.

[...] e ler é potencializar esta 'vida humana', é viver ao extremo, emocionando-se, comovendo-se, não limitando-a para 'apenas conhecer' [...] A vida com leitura é uma forma de potencializar a vida corriqueira. Viver com leitura é elevar-se, para além da vida prosaica, comum, em que cabe também o 'simples' conhecer. A vida com leitura é, então, uma vida de intensa prática de prazer (ASSUMÇÃO, 2000, p. 56).

Miguel e Freire (2016) reportam que é ávido o interesse das instituições em avaliar a qualidade, visando aprimorar e desenvolver o processo de serviços e, consequentemente, reter e atrair a clientela. Mas, no que tange uma feira literária (do livro e da leitura) como é pensada a questão da qualidade? Como avaliar um serviço? Quais valores são transmitidos para aos cidadãos? Qual legado deixa para a sociedade? Cabe lembrar que a $1^{\underline{a}}$ Bienal do Livro de Juiz de Fora pode proporcionar a experiência de criação de laços mais sólidos entre os autores e seus leitores e, sobre o slogan 'Abrindo novas Páginas Para a Vida' o evento sinaliza que novos autores e eventos literários se espalham pelo país (VALENTE, 2009).

Tais acontecimentos corroboram as considerações de Paranhos (2015), ao explanar as circunstâncias históricas que entrelaçam a cultura livresca.

A comunicação científica desempenha função de suma importância porque consiste na divulgação dos resultados das pesquisas à comunidade científica e a outros especialistas interessados, de forma a favorecer a geração e a disseminação de conhecimentos e de atividades de pesquisas. É a troca de informações científicas que favorece ao produto (produção científica) e aos produtores (pesquisadores) a necessária visibilidade e possível credibilidade no meio social em que os mesmos se inserem (MACHADO JÚNIOR, 2013).

A História do Livro é um tipo de conhecimento que estuda os vários tipos de suporte e escrita desde seus primórdios. A História das Bibliotecas se mostra complementar à História do Livro, não sendo possível contar a história de um sem comentar sobre o outro. [...] Para a História do Livro, é 
imprescindível se estudar a vida das pessoas que viveram e participaram das mudanças que afetaram de tal objeto. Foram eventos positivos e negativos que nos trouxeram até aqui. Diferente do que se pensa, a História do Livro foi tumultuada, tendo em seu decorrer pessoas ambiciosas, idealistas, lutadoras e visionárias que tiveram tantas necessidades que transformaram a propagação do conhecimento nas civilizações antigas, quanto censuras de reis, monarcas, ditadores e Igrejas, além das inúmeras disputas de poder, guerras que influenciaram de todos os ângulos possíveis a história aqui apresentada (PARANHOS, 2015, p. 18).

De um modo geral, grandes são os desafios para 'viver com leitura' e, fomentar a construção de valorização do livro. E nesse processo, ser uma 'cidade educadora' é gerar uma feira literária, é primar de forma impar pelos escritores locais, trazer o crescimento intelectual e movimentar o mercado editorial. Nessa perspectiva, Barbosa (2004) ressalta que a dimensão carnavalesca do universo medieval também transforma os espaços de racionalidade econômica - as feiras - em lugares de prazeres, desregramentos e exposição do exótico.

\section{REFERENCIAL TEÓRICO}

A gestão da qualidade sempre esteve presente na vida do homem e seu enfoque implica um processo contínuo e recorrente de se organizar para sobreviver, modificando para favorável (onde for negativa) a imagem da instituição junto a seus públicos prioritários (MIGUEL; FREIRE, 2016).

Chiavenato (2003) alega que a "melhoria contínua da qualidade" é uma técnica de mudança organizacional suave e contínua, centrada nos produtos e serviços dentro de programas de longo prazo que privilegia uma melhoria gradual que perpassa a colaboração e participação efetiva das pessoas. Apesar de todas as transformações ocorridas na última década, torna-se necessário analisar especialmente a gestão do processo de desenvolvimento de serviços, marcado, possivelmente, pelo coevo desdobramento do contingenciamento de despesa que assola o país.

Enquanto serviço é trabalho em processo, produto, por outro lado, é o resultado deste processo, ou seja, é um trabalho acumulado, um trabalho objetivado (...) fundamentalmente diferente de um bem ou de um produto. Serviço é trabalho em processo, e não o resultado da ação do trabalho; por esta razão elementar, não se produz um serviço, e sim se presta um serviço (MEIRELLES, 2006, p. 131).

Conceitualmente a 'qualidade' pode ser definida de distintas formas e, para essa investigação escolheu-se o conceito de Parasuraman, Zeithaml e Berry (1985); que consideram a qualidade como a diferença entre as expectativas dos clientes sobre o serviço a receber e suas percepções sobre os serviços efetivamente realizados. Em conformidade com esses autores surge um modelo conceitual de qualidade em serviços para identificar as lacunas (ou gaps) que causam problemas na prestação de serviços. Os critérios de avaliação aplicados levam em consideração as brechas (os hiatos) que expressam as diferenças entre as expectativas da clientela e o que é realmente oferecido (MIGUEL, 2017).

Parasuraman, Zeithaml e Berry (1985) avistaram que os gaps são grandes obstáculos na tentativa de se atingir um nível de excelência, e no que tange a questão da qualidade propuseram um modelo de avaliação de satisfação com foco no cliente. Esta proposta conceitual avalia a discrepância entre a expectativa da clientela em relação ao serviço e a percepção do desempenho (MIGUEL; SILVEIRA, 2017). Convém lembrar que esse modelo conceitual constatou que os clientes utilizam os mesmos critérios, 
independentemente do tipo de serviço considerado, para avaliar a qualidade. Nessa via é possível estruturar cincos dimensões avaliativas: tangibilidade (tangibles), confiabilidade (reliability), sensibilidade/receptividade (responsiveness), segurança/garantia (assurance) e empatia (empathy).

\begin{abstract}
Confiabilidade: A capacidade de prestar o serviço prometido de modo confiável e com precisão. Tangibilidade: A aparência física de instalações, equipamentos, pessoal e materiais de comunicação. Sensibilidade: a disposição para ajudar o cliente e proporcionar com presteza um serviço. Segurança: 0 conhecimento e a cortesia de empregados e sua habilidade em transmitir confiança e confiabilidade. Empatia: A atenção e o carinho individualizados proporcionados aos clientes (BERRY; PARASURAMAN, 1992, p. 30).
\end{abstract}

O Modelo Conceitual da Qualidade de Serviço (gaps model) de Parasuraman, Zeithaml e Berry (1985) instrumentaliza uma escala ${ }^{1}$ de múltiplos itens - composta por 44 sentenças (22 itens para expectativa em relação ao serviço e, os demais, abrangendo a percepção do desempenho). 0 paradigma proposto envolve a esquematização do construto "qualidade de serviços" apresentando, situações em que podem ocorrer uma lacuna entre as expectativas e percepções da clientela.

\begin{abstract}
Para esta análise dos gaps pode-se utilizar duas ferramentas: o Benchmarking ou o Servqual. A primeira seria mais utilizada para uma comparação entre o desempenho da concorrência e a organização prestadora de serviço, enquanto a segunda seria mais utilizada para uma análise da percepção dos clientes em relação à sua experiência com os serviços prestados pela organização prestadora do serviço e com serviços semelhantes prestados pelos concorrentes (MELLO et al., 2010, p.175).
\end{abstract}

Cabe lembrar que adotamos uma abordagem (re)adaptada a qual Miguel e Freire (2016) retratam como: abordagem teórico-metodológica Servqual. Nesse sentido, defende-se que a Métrica Servqual prevê um construto teórico sobre numerosos conceitos, tais como: qualidade, satisfação, percepção, expectativa, serviços, desejos, necessidades, entre outros conceitos e, ao mesmo tempo, apresenta uma metodologia científica capaz de levar à concretização de delineamentos que tenham como objeto de estudo a satisfação dos usuários dos serviços prestados por quaisquer organizações. E, tal corpus teórico torna viável aferir a qualidade para num panorama em que os serviços prestados podem variar. Por fim, é necessário reiterar que cada indivíduo que constitui uma equipe de trabalho possui jeitos e características de recepcionar e acolher, modos de se colocar à disposição, de compreender, 'ser e fazer' singulares em pró da qualidade no processo de desenvolvimento de serviços (MIGUEL, 2017).

Rocha e Silva (2016, p. 36) argumentam que o "conjunto das expectativas pode se transformar em satisfação ou decepção do usuário sobre o que ele considera qualidade". E, com esse entendimento fomos a campo realizar um diagnóstico sobre os serviços ofertados e conhecer as expectativas e percepções da clientela na $1^{\underline{a}}$ Bienal do Livro de Juiz de Fora. Nessa via, a 'natureza' sui generis da abordagem teórico-metodológica Servqual reporta que para avaliar têm que haver primeiramente uma previa experiência com o serviço em

${ }^{1}$ A escala Servqual constituída de 22 sentenças: 1, 2, 3 e 4 questões refere-se a dimensão tangibilidade; $5,6,7,8$ e 9 referem-se à confiabilidade; 10, 11, 12 e 13 à receptividade; 14, 15, 16 e 17 à segurança e por fim, as sentenças 18 a 22 referem-se à empatia. Em suma, os entrevistados respondem a essas sentenças com base em suas expectativas (desejo) e numa segunda etapa, com base no serviço que receberam. 
questão; então para identificar os pontos que podem ser melhorados no evento e viabilizar ações de melhoria; os clientes são abordados após a visitação a Bienal.

\section{PROCEDIMENTOS METODOLÓGICOS}

A seguir serão explanados os procedimentos empregados, esclarecendo a ambiência da pesquisa e os procedimentos de coleta.

\subsection{Ambiência da pesquisa}

A 1 a Bienal do Livro contou com 45 estandes de editoras, livrarias e distribuidoras locais e nacionais em um espaço de 2.600 metros quadrados no Centro de Convenções do Independência Trade Hotel (avenida Presidente Itamar Franco 3800 - Cascatinha, Juiz de Fora - MG). Esse evento teve 60 horas de programação cultural, para 60 mil visitantes, distribuídas em seis dias.

"Abrindo Novas Páginas para a Vida" foi o tema da feira que aconteceu entre os dias 14 e 19 de junho de 2016, das $9 \mathrm{~h}$ às $22 \mathrm{~h}$. A iniciativa e realização do evento ocorreram com a direção da empresa Signa Eventos; a produção e comercialização sob a responsabilidade da F. Works Produtora; curadoria da Universidade Federal de Juiz de Fora (UFJF), montagem oficial da JCC; apoio da TV Integração (afiliada Globo em Juiz de Fora), Câmara Brasileira do Livro (CBL) e da Câmara Mineira do Livro (CML); e divulgação na web, página do Sistema CFB/CRB - Conselho Federal de Biblioteconomia e Conselho Regional de Biblioteconomia. E ainda, a Secretaria de Educação de Juiz de Fora divulgou comunicado informando aos professores que as compras dos livros efetuadas na Bienal poderiam ser usadas como prestação de contas da Ajuda de Custo para Valorização do Magistério (ACVM) no ano de 2016.

Com facilidade, podemos citar que as escolas públicas e particulares tiveram como agendar (via telefone) visitas para receber atendimento personalizado e, além disso, foi fornecido mapas de bolso com a localização dos stands e boletins informativos do que sucedeu no dia anterior no site do evento. Convém lembrar que houve distribuição de flyers, sacolas personalizadas, apresentações musicais, exposição de pinturas (quadros de 19 artistas plásticos que criaram obras a partir de trechos de textos de livros), diversas manifestações artísticas, com diferentes estilos e referências.

Em relação à infraestrutura, o público teve opções de estacionamento no próprio Independência Trade Hotel e no espaço do Independência Shopping (que fica ao lado); além disso, a prefeitura Municipal de Juiz de Fora (PMJF) por meio da Secretaria de Transporte e Trânsito (Settra), auxiliou no controle de trânsito no local. Outra atração nessa feira foi à disponibilização de espaço para os food trucks e bike trucks.

\subsection{Procedimentos de coleta de dados}

Com base na abordagem, a metodologia deste estudo possui caráter descritivo de natureza quantitativa. Seu delineamento é do tipo levantamento (survey) com a utilização de questionário semiestruturado disponibilizado entre os dias 14 e 19 de junho, das $13 \mathrm{~h}$ às $19 \mathrm{~h}$, no hall do complexo Independência Trade Hotel - Centro de Convenções, sendo o instrumento de coleta de dados aplicado após o/a visitante deixar a bienal.

Para a coleta de dados utilizou-se a abordagem teórico-metodológica Servqual, com as dimensões ou determinantes da qualidade adaptadas à realidade em estudo. 0 roteiro de perguntas possuía quatro perguntas fechadas (faixa etária, gênero, etnia, município), um espaço aberto (retângulo) para captar sugestões e, vinte e dois pares de sentenças de opinião, elaboradas e distribuídas entre as cinco dimensões da qualidade para avaliar o grau de 'expectativas' e da 'percepção' perante a escala psicométrica de Likert.

Os visitantes da 1aㅡ Bienal do Livro deveriam assinalar uma opção entre 1 e 5, na ordem escalar de Likert, para o item 'importância' (sendo que na escala 1=menos importante 
e 5=muito importante) e também para o item 'satisfação' (sendo que na escala 1=insatisfeito e $5=$ muito satisfeito). Ao final, foi incluído um espaço aberto, estimulando os transeuntes a registrarem seus comentários, sugestões ou reclamações.

Em convergência com Crossno et al. (2001), elegemos o termo 'importância' ao invés de expectativas, proposto pelo método Servqual, porque essa abordagem permite ajustes e, tal entendimento simplifica a compreensão dos termos da pesquisa pelos visitantes: é mais fácil entender - 'o quanto atendimento da feira do livro é importante para você' do que 'qual a sua expectativa em relação ao atendimento'. Pela mesma razão, o termo percepção foi substituído por 'satisfação' na esquematização das questões.

Para interpretação dos resultados da pesquisa quantitativa foram utilizadas técnicas estatísticas (análise descritiva) como auxilio do software Excel da Microsoft; o qual disponibiliza fórmulas estatísticas para calcular os desvios, frequência, médias, proporções, tabelas e gráficos visando facilitar a descrição dos dados angariados.

\section{RESULTADOS E DISCUSSÃO}

Um total de setecentos e cinquenta questionários foram aplicados a população estabelecida em estudo. Foram considerados apenas os questionários que tinham a resposta 'Sim' à questão: 'Você já conheceu os espaços da bienal, tal como: os bate-papos literários, contação de história, palestras, oficinas, tarde de autógrafos, noite de lançamentos, mesa de debates, oficina de origamis, workshop para professores, momento youtuber, espaço gourmet, corredor de arte e música, stand de vendas, site e boletim da bienal'? Convêm relembrar que aplicação da abordagem teórico-metodológica Servqual requer uma prévia experiência com o serviço ofertado (MIGUEL; SILVEIRA, 2017).

Tabela 1: Perfil social dos participantes

\begin{tabular}{|c|c|c|c|}
\hline \multirow{3}{*}{ Perfil Social } & \multicolumn{3}{|l|}{ Mesorregião } \\
\hline & Campo das Vertentes & Sul Fluminense & Zona da Mata \\
\hline & $\mathrm{N}=65$ & $\mathrm{~N}=100$ & $\mathrm{~N}=235$ \\
\hline \multicolumn{4}{|l|}{ Faixa etária } \\
\hline$<20$ & 33 & 58 & 121 \\
\hline $20-40$ & 22 & 25 & 76 \\
\hline$>40$ & 10 & 17 & 38 \\
\hline \multicolumn{4}{|c|}{ Cor da pele (etnia) } \\
\hline Amarela & 11 & 8 & 24 \\
\hline Branca & 27 & 55 & 98 \\
\hline Preta (negro) & 9 & 17 & 44 \\
\hline Parda & 18 & 20 & 69 \\
\hline \multicolumn{4}{|c|}{ Gênero (orientação sexual) } \\
\hline Masculino & 35 & 57 & 129 \\
\hline Feminino & 28 & 40 & 99 \\
\hline Outro (a) & 2 & 3 & 7 \\
\hline
\end{tabular}

Fonte: Dados da pesquisa (2016).

Com a tabela cima (Tabela 1) obtemos uma breve identificação da comunidade abordada - e assim, verifica-se que a maioria dos respondentes 212 (53\%) são jovens com menos de 20 anos; a etnia predominante autodeclarada é branca 180 (45,00\%) e sobressai a participação de respondentes do gênero masculino $221(55,25 \%)$.

\subsection{Importância e satisfação}

Uma análise dos resultados permite identificar os itens mais importantes, ou seja, as expectativas da comunidade usuária e, 'Equipe de pessoas gentis e acessíveis' obteve 85\% das respostas e 'Equipe sempre disposta para ajudar nas dúvidas e demandas' obteve 82\%. 
Ainda em relação à importância, os itens da pesquisa receberam dos participantes uma pontuação que variava entre 4,25 e 4,75 de uma escala de cinco pontos. Isso sugere que os fatores selecionados no diagnóstico são de fato proeminentes para a clientela da bienal.

Entre os itens apontados como de 'maior satisfação', o primeiro deles, com $84 \%$ das respostas foi 'Atendente tem conhecimento suficiente para responder minhas questões relativas ao evento', e o segundo, com 80\%, 'Equipe inspira segurança'. Ainda em relação à satisfação (percepção), os participantes atribuíram às questões, uma pontuação que variava entre 3,90 e 4,60 de uma escala de cinco pontos, assinalando uma pequena diferença entre a importância e a satisfação dos serviços. Entretanto, os itens que alcançaram uma pontuação menor podem representar aspectos a serem melhorados nos serviços ofertados na $1 \underline{\text { a }}$ Bienal do Livro da Zona da Mata (no sudeste de Minas Gerais). Entre eles estão as 'Instalações físicas adaptadas às necessidades dos visitantes' e 'Instalações físicas (salas de aula banheiros, recepção) visualmente agradáveis', ambos apresentando respectivamente 15\% das respostas marcadas entre 'insatisfeito' e 'pouco satisfeito'.

A tabela 2 apresenta a média da pontuação (em uma escala de 1 a 5) recebida pelos indicadores da qualidade de serviço a respeito da importância e satisfação, agrupados por dimensão:

Tabela 2: Importância e satisfação por dimensão

\begin{tabular}{lcc}
\hline Dimensão & Importância (e) & Satisfação (p) \\
\hline Confiabilidade & 4,70 & 4,35 \\
Empatia & 4,25 & 4,00 \\
Garantia & 4,65 & 4,60 \\
Receptividade & 4,50 & 4,40 \\
Tangibilidade & 4,75 & 3,90 \\
\hline
\end{tabular}

Fonte: Dados da pesquisa (2016).

A determinante da qualidade do serviço assinalada nesse trabalho distingue a dimensão Tangibilidade (tangibles) como sendo a preferida pela clientela da I Bienal do livro em Juiz de Fora. Em contracena, essa mesma dimensão designa as aparências físicas das instalações, equipamentos, pessoal e material de comunicação, e expõe o índice mais rebaixado (entre as dimensões da qualidade) no que tange a satisfação ou percepção do que de fato foi encontrado (lacuna).

\subsection{Análises de quadrantes e de gaps}

Nitecki e Hernon (2000) recomendam a Matriz Importância e Desempenho (Análise de Quadrante), que consiste em uma correlação gráfica que facilita a visualização das informações, compreendendo uma ferramenta teórico-metodológica da estratégia organizacional: manter, aperfeiçoar, realocar recursos, rever esforços.

A análise se constrói por uma matriz bidimensional, em que a importância é mostrada pelo eixo $\mathrm{X}$, e se atribui ao eixo $\mathrm{Y}$ a satisfação. Um atributo que se situar no quadrante I terá alta importância com alto desempenho, representando uma possível vantagem competitiva. Um atributo que tiver alta importância, mas baixo desempenho deverá receber atenção imediata, constando no Quadrante II. O Quadrante III concentra os atributos com alto desempenho, porém com baixa importância. O Quadrante IV contém os atributos com baixa importância e baixo desempenho, não sendo necessário concentrar esforço adicional.

Nessa bienal do livro (Zona da Mata), sobreveio uma concentração no quadrante 1 (manter) de todos os vinte e dois atributos da qualidade, e isso sugere que a clientela da bienal vê todos esses atributos como sendo altamente importantes e bem desempenhados pela feira, como pode ser vislumbrado na Figura 1. 


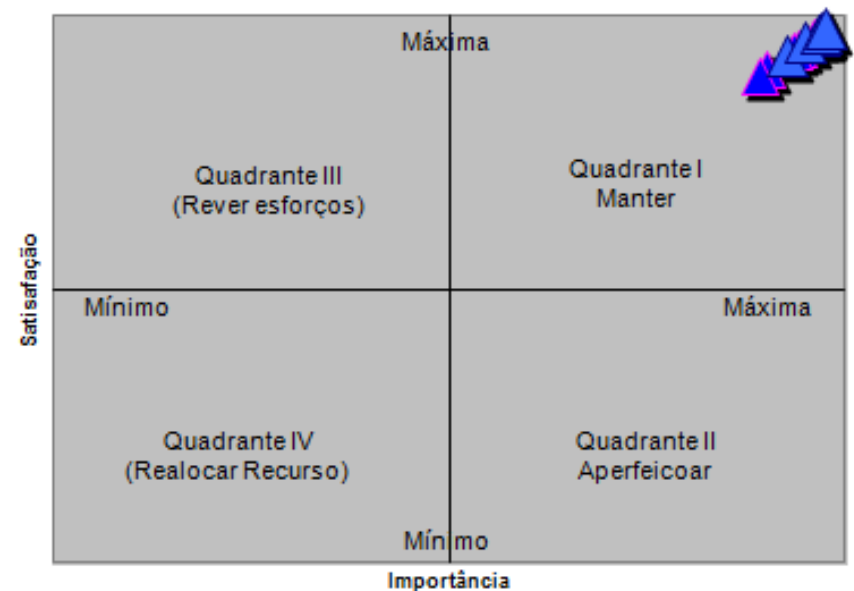

Figura 1: Análise de Quadrantes

Fonte: Dados da pesquisa (2016).

Brito e Vergueiro (2011) reportam que a "análise de gaps" é uma excelente maneira para apresentar os resultados da pesquisa, e para o cálculo dos gaps emprega-se a seguinte fórmula: 'Gap = Satisfação - Importância'.

Para calcular as médias, as pontuações (de 1 a 5 ) de cada item são somados e depois divididos pelo número total de respondentes (400) - tanto para a satisfação quanto para a importância. 0 modelo Servqual considera a qualidade como a diferença entre percepção de desempenho e expectativa (MIGUEL; SALOMI, 2004; ROCHA; SILVA, 2016; MIGUEL, 2017; SILVEIRA; MIGUEL, 2018) e assim calcula-se a seguir a diferença entre as duas, obtendo-se o gap por questão.

Nitecki e Hernon (2000) assinalam em seus estudos que as pontuações de gaps entre 0 e -1 não superam as expectativas (excelência), contudo podem atender ao que os usuários esperam de um serviço padrão e, granjeando uma qualidade positiva ao serviço prestado.

Para o cálculo dos gaps por dimensão foram somadas as médias dos itens de cada determinante e divididas pelo total de questões de cada dimensão contida no questionário aplicado. Por exemplo, para o cálculo dos gaps da determinante Receptividade, foram somadas as médias das pontuações das questões relativas a esta dimensão, e depois divididas por quatro, que era o número de itens relacionados a esta dimensão. A figura 2 apresenta os gaps por dimensão da qualidade em serviços:

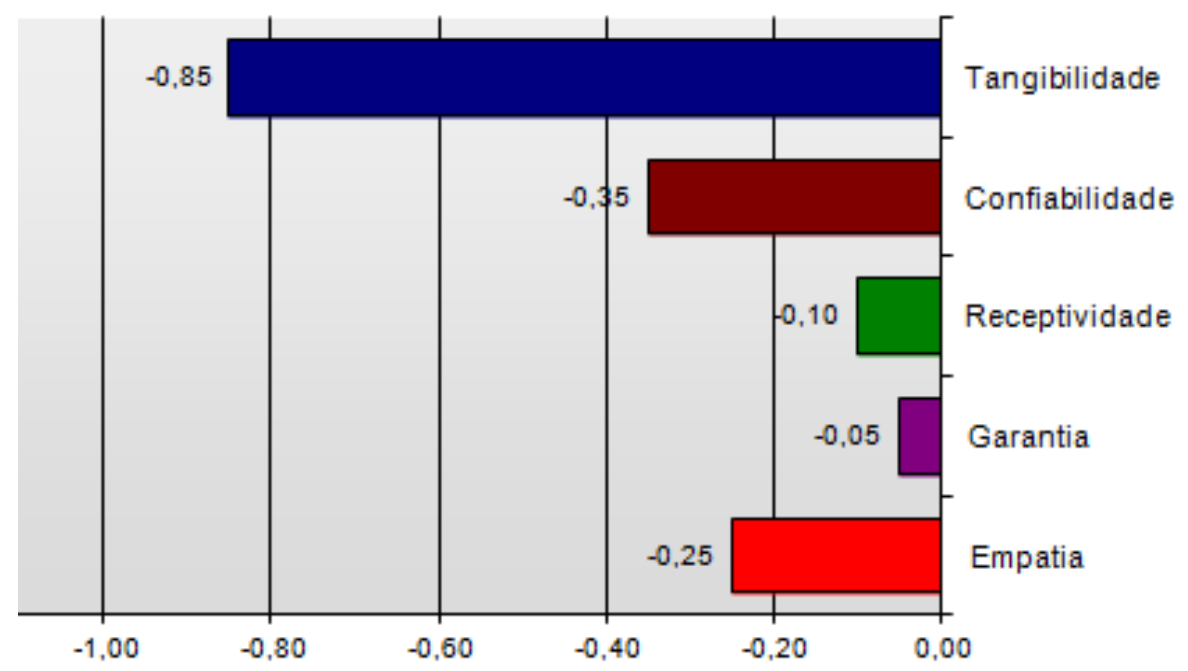

Figura 2: Gráfico dos gaps por dimensões

Fonte: Dados da pesquisa (2016). 
A partir da figura 2 pode-se averiguar os hiatos entre o 'serviço desejado' e o 'de fato encontrado', sendo que a maior lacuna abrange a determinante Tangibilidade. Ao que tudo indica, essa lacuna demonstra que atratividade das instalações físicas é um ponto crucial para a qualidade do serviço - pois influencia não somente a percepção da ambiência, mas também as expectativas quanto a desenvoltura do processo de desenvolvimento dos serviços ofertados. Nesse cenário de gaps por dimensões, verificamos a diferença entre o serviço desejado e o encontrado, e a dimensão Garantia apresenta menor divergência. Isso indica que não houve decepção significativa, ou seja, os visitantes ratificam a percepção efetiva da 'Capacitação' da equipe em desenvolver os serviços na bienal.

Em síntese, as publicações dos artigos brasileiros estão mais concentradas em alguns periódicos científicos que se relacionam diretamente às instituições que se destacaram em quantidade de artigos publicados, já as pesquisas publicadas no exterior não se apresentam concentradas em poucos periódicos.

\section{CONSIDERAÇÕES FINAIS}

Este estudo foi realizado tendo-se como objetivo principal avaliar a qualidade dos serviços prestados pela $1 \underline{\text { a }}$ Bienal do Livro de Juiz de Fora no que tange a expectativa e a percepção dos visitantes em relação aos serviços ofertados. Assim, concordamos com Rocha e Silva (2016) que reportam que grande é o interesse que atualmente desperta a temática da qualidade, tanto em nível acadêmico, como em nível profissional na contemporaneidade.

Por meio dessa pesquisa foi possível constatar que os visitantes da I Bienal percebem positivamente a qualidade, mas apontam que a parte tangível dos serviços pode ser melhorada, evitando tumultos desnecessários, e organizando melhor o ambiente da exposição. Observa-se que o cálculo do gaps por dimensões aponta leves discrepâncias entre importância e satisfação, indicando que existe uma lacuna para esse evento, e atingir a qualidade é uma filosofia que requer averiguar as necessidades e desejos da clientela.

Um dos pontos fracos refere-se aos gaps da dimensão tangibilidade, que demonstra a necessidade de se investir na melhoria da infraestrutura física e tecnológica - no que tange a fatores de acessibilidade, organização e fluidez dos espaços. Diante disso, cabe sugerir espaço para relaxamento, convivência, qualidade da banda larga e redes sem fio (wi-fi), climatização do ambiente, adequação dos recursos de multimídia.

A primeira Bienal do Livro de Juiz de Fora deixa um saldo positivo para os organizadores e para um público participante. Ao longo dos seis dias de evento, foram realizadas cerca de 160 atividades culturais, entre oficinas, mesas de debate e bate-papo, e quase 40 horas de contação de histórias, mas cabe destacar que vem aumentado o número de eventos literários, tanto em cidades do interior quanto em capitais porém, falta dar mais visibilidade ao papel do bibliotecário no que tange ao aprimoramento desses eventos. Tais espaços são de suma importância para incentivar a leitura, aproximar leitores, estimular nova praticas em prol do livro e da literatura.

Entre tantos desafios em avaliar a qualidade dos serviços de uma bienal do livro destaca-se que o resultado mais satisfatório veio do feedback do público, o qual sai do evento indagando "quando será o próximo" - abraçando a feira. Não só a grande oferta de livros e a proximidade com seus autores atraíram os visitantes, mas a organização, o cuidado, a formação de educadores, o entretenimento cultural, o agendamento para escolas, os boletins informativos... Em suma, um processo de desenvolvimento de serviços primoroso.

Reiteramos que os visitantes atendidos na I Bienal do Livro de Juiz de Fora (Zona da Mata Mineira), estão satisfeitos com o atendimento ofertado na feira, citando a 'tangibilidade' como uma das mais importantes, no entanto, tal dimensão merece cautela. É pertinente considerar que esta pesquisa comprovou que o método Servqual é apropriado para avaliar a qualidade a partir das percepções e expectativas dos clientes de forma abrangente. 
Além disso, essa abordagem teórico-metodológica visa o monitoramento e avaliação permeados pela articulação, negociação ou controle, como elementos de comunicação, quer seja do desejo de algo ou das necessidades desse serviço em prol da comunidade. Uma desvantagem do método em questão é o fato do questionário padrão do Servqual ser constituído apenas por questões fechadas, o que o caracteriza como um método quantitativo. Todavia, nessa pesquisa, primamos suprir essa lacuna inserindo espaço para sugestões e, adequando a abordagem ao meio social. Portanto, não basta fornecer serviços com excelente qualidade, é necessário que o cliente esteja no centro do processo de desenvolvimento de serviços.

Certamente este tema não se esgota nesse estudo, mas reafirma a necessidade de compreendermos o desvelamento dos dilemas e vicissitudes de um processo de desenvolvimento de serviços. Sugerimos explorar mais a parte qualitativa da adaptação do método Servqual, elaborando um diagnóstico mais aprofundado do discurso dos entrevistados. Por isso, possíveis desdobramentos podem fundamentar um fortalecimento dessa abordagem nos diversos espaços não formal de educação.

Finalmente, no elenco de preocupações com a qualidade, deve se considerar que uma avaliação não é fim em si, mas deve ser realizada com o objetivo de exprimir em oportunidades de aplicabilidade de boas práticas (best practices), melhoria e inovação. Cabe salientar que a aplicação da abordagem diante aos avanços das Tecnologias de Informação e Comunicação (TIC) pode ser facilmente aplicada online com apoio das ferramentas Google Forms, da suite Google Docs, e de tantos outros recursos para dinamizar a retificação de lacunas presente. Agora fica pontos pertinentes para trazer uma $2^{\underline{a}}$ edição para 2018 ainda melhor, e assim fechamos esse painel com a "suntuosa e derradeira" hashtags (da bienal) "\#aquitemgratidão".

\section{REFERÊNCIAS}

ASSUMÇÃO, J. Máquina de destruir leitores. Porto Alegre: SULINA, 2000.112 p.

BARBOSA, L. Sociedade de consumo. Rio de Janeiro: J. Zahar, 2004. 68 p.

BERRY, L. L.; PARASURAMAN, A. Serviços de marketing: competindo através da qualidade. São Paulo: Maltese: Norma, 1992. $238 \mathrm{p}$

BRITO, G. F. de; VERGUEIRO, W. C. S. Avaliação da Qualidade Orientada ao Usuário estudo de caso em biblioteca acadêmica utilizando o método SERVQUAL. Ciencias de la Información, Havana, v. 42, n.2, p. 55-59, maio/ago. 2011. Disponível em: <http://www.redalyc.org/pdf/1814/181422294009.pdf>. Acesso em: 08 mar. 2016.

BURKE, P. Uma história social do conhecimento II: da enciclopédia à Wikipédia. Rio de Janeiro: Zahar, 2012. 414 p.

CHIAVEnATO, I. Teoria Geral da Administração. 7.ed. São Paulo: Editora Campus, 2003.

CROSSNO, J. E. et al. Assessment of customer service in Academic Health Care Libraries (ACSAHL): an instrument for measuring customer service. Bulletin of the Medical Library Association, Bethesda MD, v. 89, n. 2, p. 170-176, Abr. 2001. Disponível em: <http://www.ncbi.nlm.nih. gov/pmc/articles/PMC31724/>. Acesso em: 17 mar. 2015.

MEIRELLES, D. S. O conceito de serviço. Revista de Economia Política, São Paulo, v. 26, n. 1, p. 119 136, mar. 2006. Disponível em: <http://dx.doi.org/10.1590/S0101-31572006000100007>. Acesso em: 18 set. 2015

MELLO, C. H. P. et al. Gestão do processo de desenvolvimento de serviços. São Paulo: Atlas, 2010 VIII, $194 \mathrm{p}$. 
MIGUEL, M. C. Múltiplos olhares em prol da qualidade de serviços biblioteconômicos. Revista ACB, Florianópolis, v. 22, n. 2 especial, p. 192-207, jul. 2017. Disponível em:

<https://revista.acbsc.org.br/racb/article/view/1312>. Acesso em: 20 dez. 2017.

MIGUEL, M. C; FREIRE, V. F. Avaliação da qualidade orientada ao usuário do museu capixaba do negro: aplicação da abordagem teórico-metodológica Servqual em um espaço museológico de Vitória-ES. Revista Guará, Vitória, n. 05, p. 103-116, jul. 2016. Disponível em: <http://periodicos.ufes.br/guara/article/view/14350/10092>. Acesso em: 19 jul. 2017.

MIGUEL, M. C.; SILVEIRA, R. Z. Percepções e expectativas dos associados da Biblioteca Transcol em encontro aos seus dez anos de atuação. Revista Eletrônica Gestão e Serviços, São Paulo, v. 8, n. 2, p. 2021-2041, jul./dez. 2017. Disponível em: <https://www.metodista.br/revistas/revistasims/index.php/REGS/article/view/7386>. Acesso em: 19 dez. 2017.

MIGUEL, P. A. C.; SALOMI, G. E. Uma revisão dos modelos para medição da qualidade em serviços. Prod., São Paulo, v. 14, n. 1, p. 12-30, 2004. Disponível em: <www.scielo.br/scielo.php?script=sci_arttext\&pid=S0103-65132004000100003 >. Acesso em: 22 out. 2016.

NITECKI, D. A.; HERNON, P. Measuring service quality at Yale's University's libraries. The Journal of Academic Librarianship, v. 26, n. 4, p. 259-273, jul. 2000.

PARANHOS, R. C. Personalidades da história do livro. 2015. 43 f. Monografia (Bacharelado em Biblioteconomia) - Faculdade de Ciência da Informação, Universidade de Brasília, Brasília, 2015.

PARASURAMAN, A; ZEITHAML, V. A; BERRY, L. L. A conceptual model of service quality and its implications for future research. Journal of Marketing, Chicago, v. 49, n. 4, p. 41-50, Fall 1985.

ROCHA, R. A. da, SILVA, A. A. A Métrica Servqual na Avaliação da Satisfação dos Usuários da Biblioteca Central da Universidade Federal de Santa Catarina. Encontros Bibli: Revista Eletrônica de Biblioteconomia e Ciência da Informação, Florianópolis, v. 21, n. 45, p. 35-53, jan./abr 2016. Disponível em: <http://dx.doi.org/10.5007/1518-2924.2015v21n45p35>. Acesso em: 19 ago. 2017.

SILVEIRA, R. Z. da; MIGUEL, M. C. Avaliar e (re)pensar espaços de socioambientalismo museológico: olhares sobre o Museu de história natural do sul do estado do Espírito Santo. Expressa Extensão, Pelotas, v. 23, p. 104-121, 2018. Disponível em:

<https://periodicos.ufpel.edu.br/ojs2/index.php/expressaextensao/article/view/12537>. Acesso em: 19 fev. de 2018.

VALENTE, L. Novos autores e eventos literários se espalham pelo país. Cienc. Cult., São Paulo, v. 61, n. 3, 2009. Disponível em: <http://cienciaecultura.bvs.br/ scielo.php?pid=S0009-

$67252009000300021 \&$ script=sci_arttext>. Acesso em: 19 set. 2016.

Editores do artigo: Enrique Muriel-Torrado e Adilson Luiz Pinto 